
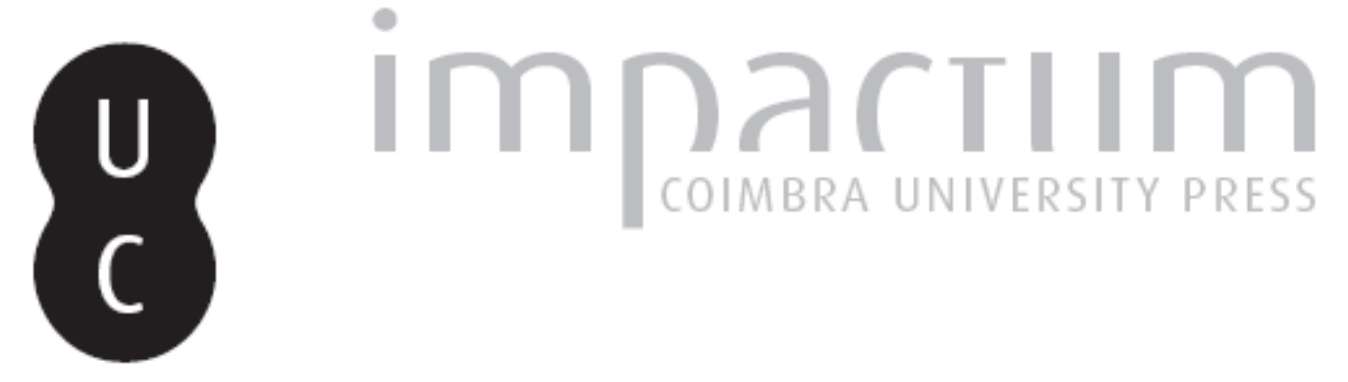

\title{
O Constitucionalismo setembrista e a Revolução Francesa
}

Autor(es): $\quad$ Silva, Júlio Joaquim da Costa Rodrigues da

Publicado por: Imprensa da Universidade de Coimbra

URL persistente:

URl:http://hdl.handle.net/10316.2/43786

DOI:

DOI:https://doi.org/10.14195/2183-8925_10_27

Accessed : $\quad$ 26-Apr-2023 11:13:36

A navegação consulta e descarregamento dos títulos inseridos nas Bibliotecas Digitais UC Digitalis, UC Pombalina e UC Impactum, pressupõem a aceitação plena e sem reservas dos Termos e Condições de Uso destas Bibliotecas Digitais, disponíveis em https://digitalis.uc.pt/pt-pt/termos.

Conforme exposto nos referidos Termos e Condições de Uso, o descarregamento de títulos de acesso restrito requer uma licença válida de autorização devendo o utilizador aceder ao(s) documento(s) a partir de um endereço de IP da instituição detentora da supramencionada licença.

Ao utilizador é apenas permitido o descarregamento para uso pessoal, pelo que o emprego do(s) título(s) descarregado(s) para outro fim, designadamente comercial, carece de autorização do respetivo autor ou editor da obra.

Na medida em que todas as obras da UC Digitalis se encontram protegidas pelo Código do Direito de Autor e Direitos Conexos e demais legislação aplicável, toda a cópia, parcial ou total, deste documento, nos casos em que é legalmente admitida, deverá conter ou fazer-se acompanhar por este aviso.

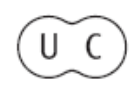


REVISTA DE HISTORIA DAS IDEIAS IO
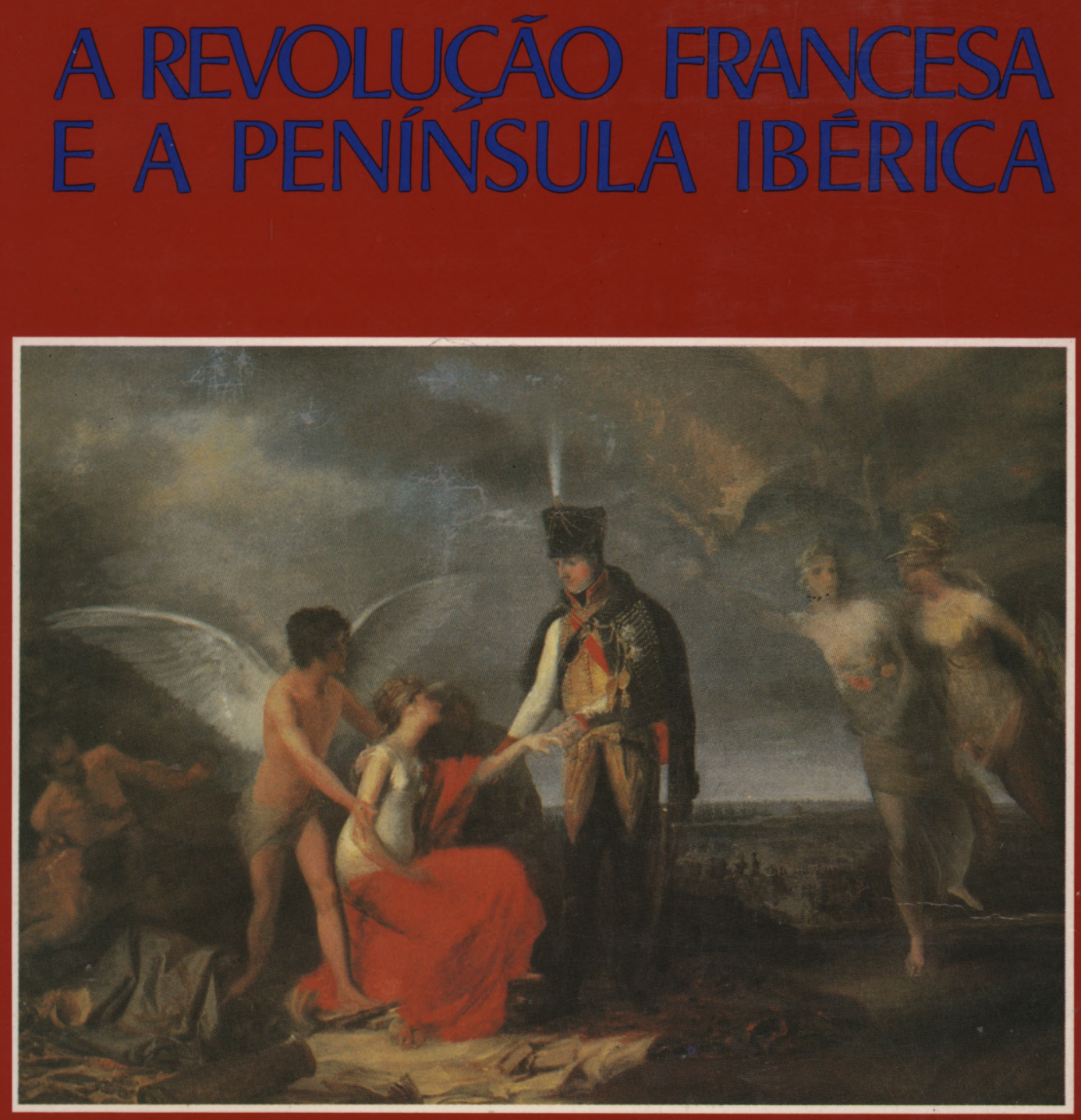

INSTITUTO DE HISTÖRIA E TEORIA DAS IDEIAS FACULDADE DE LETRAS 
JULIO JOAQUIM DA COSTA RODRIGUES DA SILVA*

\section{O CONSTITUCIONALISMO SETEMBRISTA E A REVOLUÇÃO FRANCESA}

\section{Constitucionalismo e Setembrismo}

Todo o movimento político que procura fundar em novas bases o relacionamento político-institucional duma sociedade, é levado, pela sua própria dinâmica de ruptura, a uma reinterpretação do passado.

No caso específico do Setembrismo, tal dinâmica inseriu-se numa mutação cultural, de nível europeu, que implicava, não só uma revisão geral da historiografia da Revolução Francesa, mas também a definição de novos modelos políticos e constitucionais.

Com efeito, no panorama político dos anos 20 e 30 do século XIX, marcado pela Revolução de Julho de 1830 e a Independência Belga de 1831, a Revolução Francesa foi alvo de um debate aceso entre correntes políticas opostas, já que foi considerada como o elemento central da História Política Contemporânea, o acontecimento-chave que abria uma nova era e fornecia, por si mesmo, a explicação, o sentido do presente.

O debate não se limita a uma oposição clássica direita-esquerda, mas dividiu a própria esquerda europeia entre os adeptos de 89 e os defensores de 93, implicando uma escolha entre o liberalismo inicial da Revolução e o período jacobino posterior. Conforme se optasse, por uma ou por outra dessas interpretaçōes, assim o modelo constitucional diferia.

A Revolução de Setembro levou à convocação de Cortes Constituintes Extraordinárias que, nos anos de 1837 e 1838, produziram um novo texto constitucional. No debate que então teve lugar, os deputados das Cortes recorreram a vários modelos cons-

* Bolseiro do I.C.A.L.P. 
titucionais e apresentaram numerosas justificações históricas em que a Revolução Francesa assumiu um papel essencial.

O conhecimento das diversas interpretações históricas da Revolução Francesa, permite-nos compreender o impacto que os acontecimentos de 1789 e 1793 tiveram na mentalidade de uma geração e a forma como foram integrados no imaginário político do liberalismo português da primeira metade do século XIX.

\section{Modelos constitucionais em conflito}

No momento (30 de Janeiro de 1837) em que as Cortes Constituintes se reunem, a evolução recente da Revolução de Setembro dava um aspecto diversificado às correntes ou agrupamentos políticos que, geralmente, se associam ao Setembrismo.

$\mathrm{Na}$ verdade, resultante do confluir de um largo leque de descontentes políticos com o regime da Carta, o Setembrismo agrupava no seu seio elementos de centro-direita conhecidos como Ordeiros, de esquerda moderada (ou centro-esquerda) como os Setembristas Puros Moderados e de extrema-esquerda como os Setembristas Puros Exaltados.

Os primeiros, ligados a uma aristocracia liberal dissidente do Cartismo, tinham procurado, durante o período que medeia entre o fim da Guerra Civil de 1829-1834 e 1836, fornecer uma alternativa credível quer aos governos cartistas, quer à oposição de esquerda. Os seus esforços nunca tinham conseguido ir além de periclitantes governos de «fusão» sem qualquer viabilidade.

Os segundos tinham estado em constante choque com os governos cartistas desde 1834 recuperando para si parte do ideário vintista que muitos tinham vivido enquanto participantes no processo político de 1820-1823. Eram estes que estavam mais intimamente ligados aos acontecimentos revolucionários de Setembro de 1836.

Por último, elementos oriundos duma geração mais nova que não tinha vivido directamente o Vintismo, mas que participara activamente na guerra civil contra o Miguelismo e na luta política contra o Cartismo. Este grupo, embora aliado táctico da «velha guarda» Setembrista, distinguia-se sobretudo por um radicalismo de meios e por uma exigência de acção imediata que tentava estabelecer um domínio permanente do aparelho de estado, capaz de viabilizar uma nova realidade política e social.

A estas diferentes correntes políticas correspondiam modelos constitucionais diferenciados que dependiam quer da maior $\mathrm{cu}$ menor heterogeneidade do seus membros, quer do espaço cultural em que estes se moviam. 


\section{O Constitucionalismo Setembrista}

Para os Ordeiros, o texto constitucional que lhes serve de modelo por excelência é a Constituição Francesa de 1830 e as alterações de 1831 referentes ao Pariato Vitalício. Tal opção devia-se ao seu programa político mínimo: «Desde logo assentámos no nosso programa: uma Constituição monárquica, veto absoluto e direito de dissolução; sacrificavamos os princípios hereditários e votavamos pela Camara vitalícia nomeada pelo Rei, com Categorias» $\left({ }^{1}\right)$.

Em contrapartida o Centro-esquerda setembrista optava pela Constituição Belga de 1831, sobretudo quanto à segunda câmara:

«Art. $.^{\circ} 53 .^{\circ}$ - Os membros do Senado são eleitos, em função da população de cada província, pelos cidadãos que elegem os membros da Camara dos Deputados.... Art. $.^{\circ} 5 .^{\circ}-$ Os Senadores são eleitos por oito anos e renovados em metade de quatro em quatro anos, segundo a ordem de séries determinada pela lei Eleitoral. Em caso de dissolução o Senado é integralmente renovado» (2).

A Extrema-esquerda parlamentar, coerente com o seu ideário neo-vintista, seguia a Constituição de 1822 com especial acento no seu unicameralismo. Porém, nem todos os seus membros se limitavam a uma simples aceitação do antigo texto constitucional ou a um simples «aggiornamento».

Assim, o deputado M. S. Cruz, ao apresentar às Cortes um Projecto alternativo ao da Comissão Constitucional (projecto este, aliás, nunca debatido) ia mais longe, ao tentar redefinir a Constituição de 1822 em novos termos. Não se trata aqui de nos interrogarmıs sobre quais são as influências dos textos constitucionais da Revolução Francesa em 1822, mas de detectar um retorno a esses textos fundadores através da sua reinterpretação.

Neste caso específico desempenhava um papel essencial, como elemento-chave do "Poder Legislativo ou Representativo», o Senado ou Conselho Conservador com as funções simultâneas de poder moderador, deputação permanente e Conselho de Estado. Tal órgão, estranho num defensor intransigente do unicameralismo, ia buscar a ideia de que o poder moderador devia residir nas assembleias primárias (que elegeriam tal órgão) ao Projecto de Condorcet (1793) mas também à Constituição republicana de 1793 (formação das leis, espécie de referendo) e, talvez, à Constituição Francesa de 1791.

(1) Memórias do Marquês da Fronteira, Parte VI, Vol., p. 209. p. 236 .

(2) Jorge Miranda, Textos Históricos de Direito Constitucional, 
Porém, na ideia de que era necessário um Corpo Conservador que funcionasse como uma espécie de Tribunal Constitucional, o autor vai buscar elementos às teorizações de Sieyès sobre a Constituição de 1795 e, sobretudo, à Constituição Napoleónica do ano VIII (25 de Dezembro de 1799) em que aparece um Senado Conservador. Embora, na versão de M. S. Cruz, o Senado desempenhe, como na Constituição francesa do ano VIII, um papel de «absorção política» e de neutralização de antigos rotáveis políticos, o seu carácter essencial implica a existência na sua função de «Deputação Permanente», de um papel de "conservação constitucional» que dava origem a um órgão com capacidades extremamente latas na vigilância da aplicação da constituição nos intervalos das sessões parlamentares. A esse órgão competia criar medidas extraordinárias de "salvação pública» (que passavam pela nomeação de poderes ditatoriais), a mobilização imediata da Nação e decretar uma série de medidas que tinham por objecto um verdadeiro estado de emergência, suspendendo os direitos individuais e colectivos de várias «classes e lugares». Por outro lado, no parágrafo 4 do Art. ${ }^{\circ} 93^{\circ}$ acrescentavam-se ainda as suas capacidades de: «sindicar enfim das pessoas, e classes superiores em todos os casos de omissão em matéria constitucional».

Estas diversas atribuiçōes conduziam à existência de um órgão de natureza especial, uma espécie de «Comité de Salut Public», capaz de instaurar uma verdadeira ditadura extra-parlamentar sobre o parlamento (visado significativamente), não só contra a responsabilidade individual de pessoas das «classes superiores», mas contra as próprias «classes superiores» no seu conjunto.

Tratava-se, sem dúvida, duma «represália» ou, antes, de uma medida de vigilância contra um grupo social específico (vagamente designado pelos radicais setembristas como classes superiores ou privilegiadas), abrangendo várias categorias sócio-profissionais, tais como: altos funcionários públicos (o Exército, Governo, Igreja, etc.), grandes proprietários, grandes comerciantes e industriais, aristocratas, etc.

Mas a sua actuação não se fica por aqui, pois estende a sua acção, através de medidas de simples pressão como mensagens e admoestações, quer sobre os corpos eleitos e as Cortes, quer contra várias instituições administrativas e políticas do País, onde o Senado confunde e centraliza, em si mesmo, atribuições do poder executivo, judicial e legislativo (e do antigo poder moderador).

A teorização sobre o Senado é um dos aspectos mais radicalizantes do Setembrismo de extrema-esquerda. 


\section{O Constitucionalismo Setembrista}

Com efeito, na prática é um verdadeiro «Comité de Salut Public», disfarçado sob um hipotético controlo ou ratificação das assembleias primárias e cortes mas que, na verdade, instituiu, na previsão de uma acção de contra-revolução, um órgão protagonista de uma ditadura revolucionária e da sua inerente violência. E claro que este aspecto, na linha jacobina da Revolução de 1789-1791, não podia estar presente nas moderadas Revoluções de 1812 e de 1822 e, muito menos, nos neo-vintistas portugueses ae 1838, onde a tendência era de uma maior democraticidade, mas centrada nas eleições livres (a «urna política») e num parlainento unicameral sem referência a qualquer acção popular extra- parlamentar ou a qualquer acção de um «comité revolucionário», organizador de uma ditadura revolucionária que engoliria o próprio órgão que o gerara. Assim, em 1837, esta posição extremamente irrealista e apaixonada será sempre isolada e sem seguidores.

\section{Uma visão histórica da revolução}

Fundamentando o debate constitucional que teve lugar nas Cortes Setembristas de 1837-1838 em volta dos diferentes modelos atrás referidos, encontrava-se uma concepção da História que tinha como centro uma reinterpretação da Revolução. Francesa de 1789, reinterpretação esta que está de acordo com a ideossincrasia própria de cada agrupamento político, independentemente de visões comuns da realidade histórica, resultado de uma experiência cultural semelhante.

No cerne do debate encontra-se a obra de Guizot, sobretudo a sua Histoire de la Civilisation en France $\left({ }^{3}\right)$. Nesta obra o autor faz a história da evolução e triunfo do terceiro Estado que é identificado, pelo liberalismo posterior à Revolução de Julho de 1830, com a Classe Média vitoriosa da Monarquia de Julho $\left({ }^{4}\right)$.

E esta a visão que a própria esquerda e extrema-esquerda parlamentares têm da classe média, pela voz de um dos seus principais oradores: «M. A. Vasconcelos - Sr. Presidente, eu

(3) F. Guizot, Histoire de la Civilisation en France, Paris, ed. Didier Libraire - Editeur, 1853

(4) F. Guizot, ob. cit., Tomo IV, Seizième leçon, p. 193: «L'important de cette partie de notre histoire est evident. Personne n'ignore le grand rôle que le tiers état à joué en France; il a été l'élement le plus actif et le plus décisif de la civilisation française, celui qui en a eu déterminé, en dernière analyse, la direction et la caractère...., celle qu'on a nommé le tiers état, s'est progressivement étendue, élévée, et a d'abord modifié puissament surmenté ensuite, et enfin absorbé, or à peu prés toutes les autres». 


\section{Revista de História das Ideias}

€ntendo que essa terceira classe é hoje propriamente dita a classe média....» $\left({ }^{5}\right)$.

Este triunfo da classe média, era assim assimilado ao triunfo da própria Revolução de 1789 que era a incarnação histórica da sua vitória. Deste modo escrevia o futuro republicano Armand Carrel no National: "La révolution de 1830 a emancipé les classes inférieures, comme la révolution de 89 avait emancipé les classes moyennes» $\left({ }^{6}\right)$.

É evidente que a concepção da Revolução como produto do povo, entendido e identificado com as «classes inferiores» já em ruptura, com as classes médias triunfantes, está em completa dissonância com a ideia do radicalismo português de 1837-1838.

De facto, para o liberalismo setembrista, a classe média aparecia ainda como o elemento principal do devir histórico, aglutinador dos extremos sociais e detentor do poder e prestígio social sobre as massas.

Este conceito que se exteriorizava a nível institucional, pela opção de um modelo constitucional unicameralista, na linha das Constituições revolucionárias de 1791 e 1793 ou num bicameralismo de segunda câmara electiva e temporária, implicava uma identificação dos referentes ideológico-mentais com uma certa visão da Revolução Francesa, associada, então, pela opinião pública portuguesa e por boa parte da europeia, ao terror ou seja a uma «recorrência bárbara» (como diria Guizot).

E é aqui exactamente que se faz a linha de separação entre a interpretação da esquerda e da direita setembristas.

Para a primeira, as causas da «derrapagem» que conduzem ao «terror», entendido como irrupção violenta do povo, devem-se não à turbulência natural deste, mas à opressão a que foi submetido:

«M. A. de Vasconcelos - Muito se exagerarão os temores de que em Portugal se repitam as cenas da Revolução Francesa, senão houver segunda Câmara, porque se julga que o povo é uma fera. Mas que pedia o povo quando se revolucionou na França? Pedia a cousa mais simples: ele queria a continuação dos três estados, mas que o estado do povo tivesse dois votos; comprimiram-no, ele rebentou como a pólvora, e arrasou os outros estados» (7).

Esta visão procurava mostrar que as reivindicações políticas do povo francês na Revolução de 1789 eram tão naturais que hoje pareciam ridículas pelo seu minimalismo.

(5) D.C. Tomo III, 29/09/1837, p. 48.

(8) National, 5/02/1831, a "Armand Carrel - «Oeuvres». Tomo II,

(7) M. A. de Vasconcelos, D. C. Tomo III, S.S. 29/09/1837, p. 48. 
Seja como for, o ponto chave da argumentação considerava que a única forma de respeitar a vontade popular e defender a Soberania Nacional (heranças teóricas da Revolução), consistia $\mathrm{cm}$ optar por uma só Câmara de eleição popular ou por duas câmaras também electivas. Tal facto devia-se à crença de que só a urna política permitia, através do voto, assegurar a transparência da vontade popular.

Para a direita setembrista e ordeira este discurso radical enferma de vários erros, nomeadamente o seu tom acentuadamente anti-aristocrático.

Assim, para Sabrosa, a aristocracia francesa foi quem primeiro se opôs à camarilha que rodeava o rei e que, conjugando as suas forças com as do parlamento, procurava criar uma monarquia limitada e um governo representativo.

Para defesa desse desígnio comum foi criada a Sociedade dos Amigos da Constituição com objectivos limitados e que, quando se transformou no Clube dos Jacobinos, foi abandonada pelos aristocratas, entre eles o fundador Barnave. Não foram, portanto, estes homens, que desejavam uma monarquia limitada e um governo representativo, os culpados da destruição da França, da morte do rei, das guerras europeias e de Napoleão. Eles nada tinham a ver com os bandos dos Faubourgs de Santo António e S. Marçal que, na maneira de pensar de Sabrosa, eram dirigidos por agentes estrangeiros para desacreditarem os patriotas e a Revolução. $\mathbf{E}$ foram, exactamente esses patriotas que pagaram, muitas vezes, as suas corajosas atitudes na guilhotina.

Por outro lado, não foi o veto real que levou Luís XVI ao cadafalso. mas as medidas erradas da única câmara que empurraram o rei para decisões contrárias à sua consciência.

A crítica implícita ao unicameralismo liga-se assim estritamente a acontecimentos históricos precisos como a Convenção Nacional Francesa de 1791 e o terror, por ele atribuído ao jacobinismo.

E nesta linha de pensamento que segue Derramado ao apelar para uma visão histórica explicativa da degenerescência das assembleias unicameralistas. Estabelece uma verdadeira «lei histórica» em que afirma que, independentemente da composição da câmara ser apenas de plebeus ou de aristocratas, ou ainda de ambos, o poder real fica nas mãos de alguns favoritos da maioria, uma espécie de «aristocracia», onde a ambição dos seus membros leva ao despotismo do mais hábil ou do mais forte. Este despotismo que se entende aqui, quer como um bonapartismo, quer como um absolutismo é, assim, o resultado último do Governo da Assembleia ou Convenção, sendo lógicas as refe- 
rências históricas à Revolução Francesa de 1789 e, sobretudo, à Revolução de 1793 e ao período jacobino. Seja como for, ela própria antes de atingir extremos é, por si, já suficientemente destruidora, na medida em que, como demonstra o Governo da Convenção Nacional Francesa de 1793, se tornará omnipotente, pondo em causa todos os outros poderes, segundo o testemunho do constitucionalista Boissy d'Angls.

O essencial do discurso de Boissy d'Angls, centra-se na volubilidade duma única câmara legislativa que, sob a pressão de um bcm orador, ou da força de um grupo parlamentar, ou do domínio da opinião pública e, também, do receio da acção de uma minoria bem organizada e dirigida (como os jacobinos) na conquista do poder, prejudicará o povo, desacreditará a representação nacional e, ultrapassando todos os limites, tornar-se-á omnipotente como a Convenção Francesa de 1793.

A recusa do unicameralismo e do bicameralismo electivo e temporário, assenta numa visão da Revolução Francesa de 1789 e reflecte a não aceitação completa do princípio da Soberania Nacional, procurando rodeá-lo com a presença de uma segunda câmara não electiva e de raiz aristocrática, capaz de contrabalançar os excessos da câmara de eleição popular.

\section{A Constituição de 1838}

E neste contexto cultural que emerge o texto final da Constituição de 1838 , procurando responder a algumas das questões que se levantavam na época, entroncando mais longinquamente nas questões deixadas em aberto pela Revolução Francesa e pelas sucessivas constituições produzidas na altura em França.

Assim. há em todo o Constitucionalismo Setembrista um apelo ao passado que se reveste, ao mesmo tempo, de um esforço de reelaborar, em novos termos, o presente, baseando-se numa reinterpretação da experiência histórica.

É, nesta medida, que a Revolução Francesa de 1789, ao ser redefinida pelos deputados portugueses de 1837-1838, como um elemento fundador-chave da sua história presente, aparece partilhada em vários tempos históricos, dos quais a Convenção $\mathrm{Na}$ cional, o terror e o jacobinismo aparecem como elementos de separaçăo duma leitura dum passado que se deseja exemplar!

Nestas condições, ao optarem por 1789 face a 1793, os constituintes portugueses das Cortes Setembristas, apesar das suas diferentes opções político-ideológicas, marcam também os limites aceitáveis dum passado que se queria encerrar, estabe- 


\section{O Constitucionalismo Setembrista}

lecendo, na linha da historiografia francesa da Revolução dos anos 20 e 30 do século XIX, uma interpretação da Revolução que fundamentasse o novo texto constitucional de 1838 .

A Constituição de 1838 marca, não só uma plataforma política admissível pelo Setembrismo mas, sobretudo, o peso das referências históricas no Constitucionalismo Português na primeira metade de oitocentos, marcado por um bicameralismo moderado, por um desejo de equilíbrio e por uma intervenção moderada do rei. Procurava-se, assim, definir um modelo constitucional que incarnasse uma Monarquia Constitucional, herdeira do Constitucionalismo de 1789-1791. 